\title{
Power-to-X / Electricity-to-Hydrogen in Sector Coupling An Overview \& Case Studies
}

\author{
Hammam Soliman ${ }^{1}$ and, Peter Badstue Jensen ${ }^{2}$ \\ ${ }^{1}$ Senior Sales and R\&D Manager, Ph.D, has@aalborgcsp.com \\ ${ }^{2}$ Executive Vice President Power Plants \& Integrated Energy Systems, pbj@aalborgcsp.com \\ Aalborg CSP A/S: Adress: Hjulmagervej 55, 9000 Aalborg (Denmark)
}

ABSTRACT

Shifting from fossile-fuels to renewable energy has been strongly implemented globally in the past decades. However, this shifting process has been implemented through applying more wind and PV systems as a main energy sources. The afromentioned technologies are generating electricity as a direct product, however, it is realized that electricity demand is only $20 \%$ of the overall energy usage, while transportation demand and heat demand are occupying $30 \%$ and $50 \%$, respectively. Thus the terms "electrification" and "Power-to-X" started to be commonly used and the focus has been deeply transitioned beyond electricity generation only.

This paper aims at exploring the contribution of high-temperature thermal storage to the optimization of hydrogen production as part of the Power-to- $X$ business.

Keywords: Sector Coupling, PtX, e-fuel, Hydrogen, Green Transition, Thermal Energy Storage.

\section{INTRODUCTION}

During the past decades, the primary concern and focus has been on the generation of electricity, while the current focus has been moved towards storage and utilization of the excess generated electricity in order to cover the demand of heat as illustrated in Figure 1. In this respect, substantial focus has been put on the Power-to-X (PtX) technology. The present understanding is that excess electricity must be converted directly into hydrogen by installing electrolysis systems large enough to manage the peak power from the grid, thus offering grid balancing services. There is, however, an alternative where the balancing of the grid is done through installation of large high-temperature energy storages.

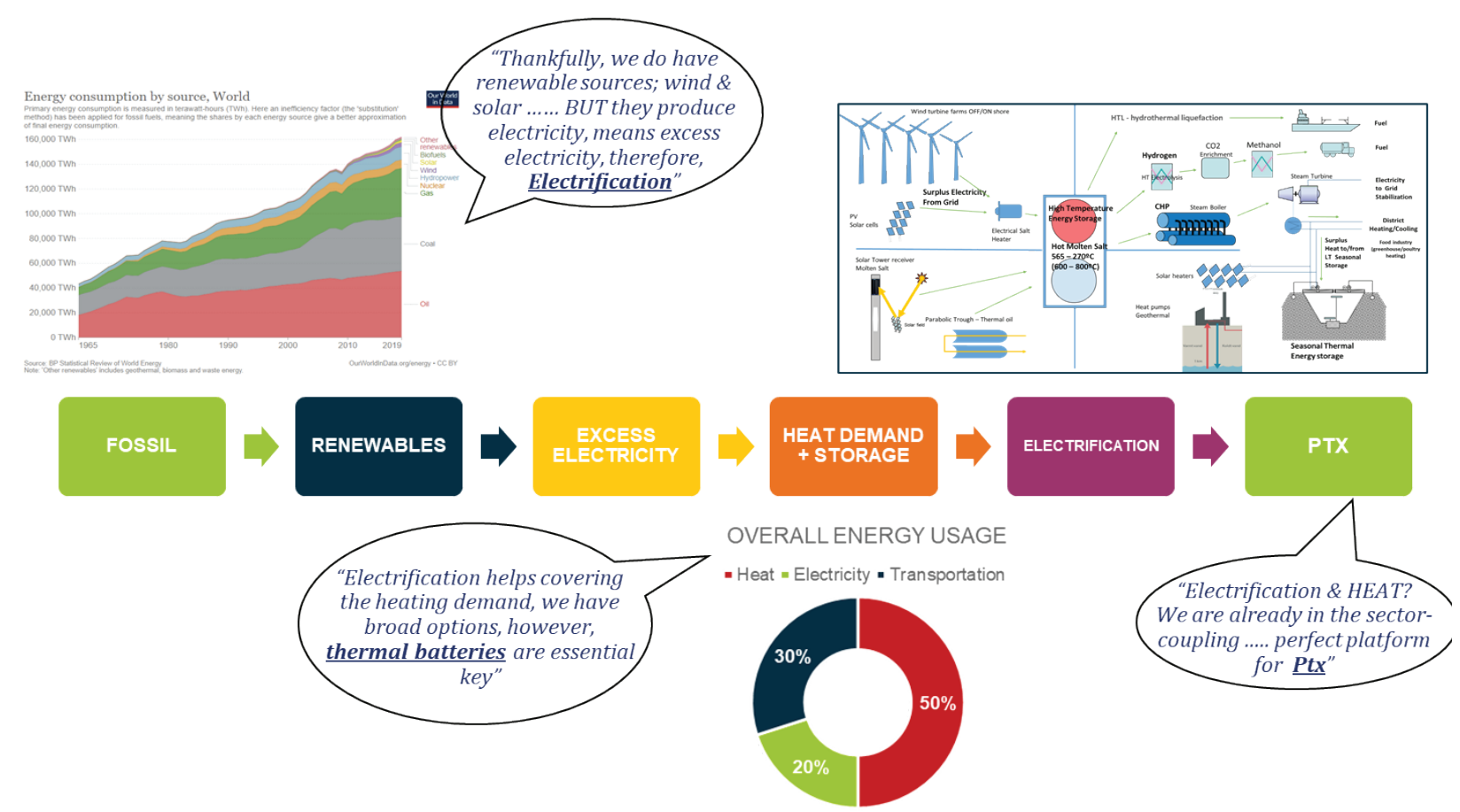

Fig. 1: Roadmap of transition from electricity generation towards PtX. 
This paper discusses the role of Power-to-X-to-Power in different applications such as: 1) The retrofitting of Coal-fired Power Plants (CPP), 2) Synergy with Wind Energy business, and 3) Hydrogen and e-fuel production.

In order to validate the retrofitting concept, a proposed case of a potential CPP in Denmark with an average installed steam turbine generation (STG) capacity of $400 \mathrm{MWe}$ is presented. In addition to the demonstration of how to apply the Power-to$\mathrm{X}$-to-Power concept to retrofit CPPs, the solution proposed also covers utilization of surplus energy generated from renewable sources such as wind and solar. Moreover, the Paper aims to explore the technoeconomical opportunities regarding the hydrogen and e-fuel production.

\section{A. Expansion of Wind \\ Farms in Synergy with \\ Power-to-X-to-Power}

The proposed solution is in perfect synergy with the continuous development of new wind farms, since wind farms can assist in energizing the EB-TES-SGS system and help phase out the coal-fired boilers. The EB block transforms electricity into heat and the TES block consists of two MS tanks - one hot and one cold. The SGS block includes the MS boiler and heat exchangers responsible for transforming the stored heat into electricity. A simplified process layout of the new EB-TES-SGS plant can be seen in Figure (2), showing the similarity of the EB-TES-SGS system that was illustrated in CPP retrofitting (Figure 4).

The electricity price in Denmark depends on the neighbouring countries, as these have same prices as nearby markets approx. 90\% of the time [4], allowing an efficient integration of renewables across borders [1]. During periods of cheap electricity, the EB can charge the TES system with electricity from the grid, typically in case of excess wind and/or PV. When the demand increases, and the price goes up, the TES is discharged and used to generate steam to drive the STG and feed electricity back into the grid. The integration to the DH network grants more flexibility, as the system can be optimized for both heat and power production.

\section{B. Power-to-X-to-Hydrogen CAPEX \& OPEX Vs. PRODUCTION}

In the past decades, the major concern was the generation of electricity, while the current era is more concerned with the use, store, and utilization of excess generated electricity. This is where the P-X-P earned more focus, especially in countries that have reached an acceptable level of maturity towards adoption of renewable technologies. Simplest definition of $\mathrm{P}-\mathrm{X}-\mathrm{P}$ is the use of electrification $(\mathrm{P})$ in the process of chemicalreaction $(\mathrm{X})$ that can still in return be able to recover part of the used energy (P), not necessary in the form of electricity. The (X) factor could be regarding production of a fuel; methanol, ammonia, hydrogen, or it could be regarding storing the excess energy in molten salt medium.

In this paper, a conceptual design of an integrated system that combines the production of hydrogen and storing energy in thermal batteries is presented. The conceptual design is based on the electrification principle via utilizing excess electricity generated from wind turbines and storing it in molten-salt storage. In such configuration, the integration of storage will give flexibility in terms of purchasing electricity during low prices, thus, optimizing the size of the electrolysis. In Figure 3a, three different hydrogen production scenarios are illustrated. The given scenarios are comparable from the import-export of electricityhydrogen, respectively, point of view.

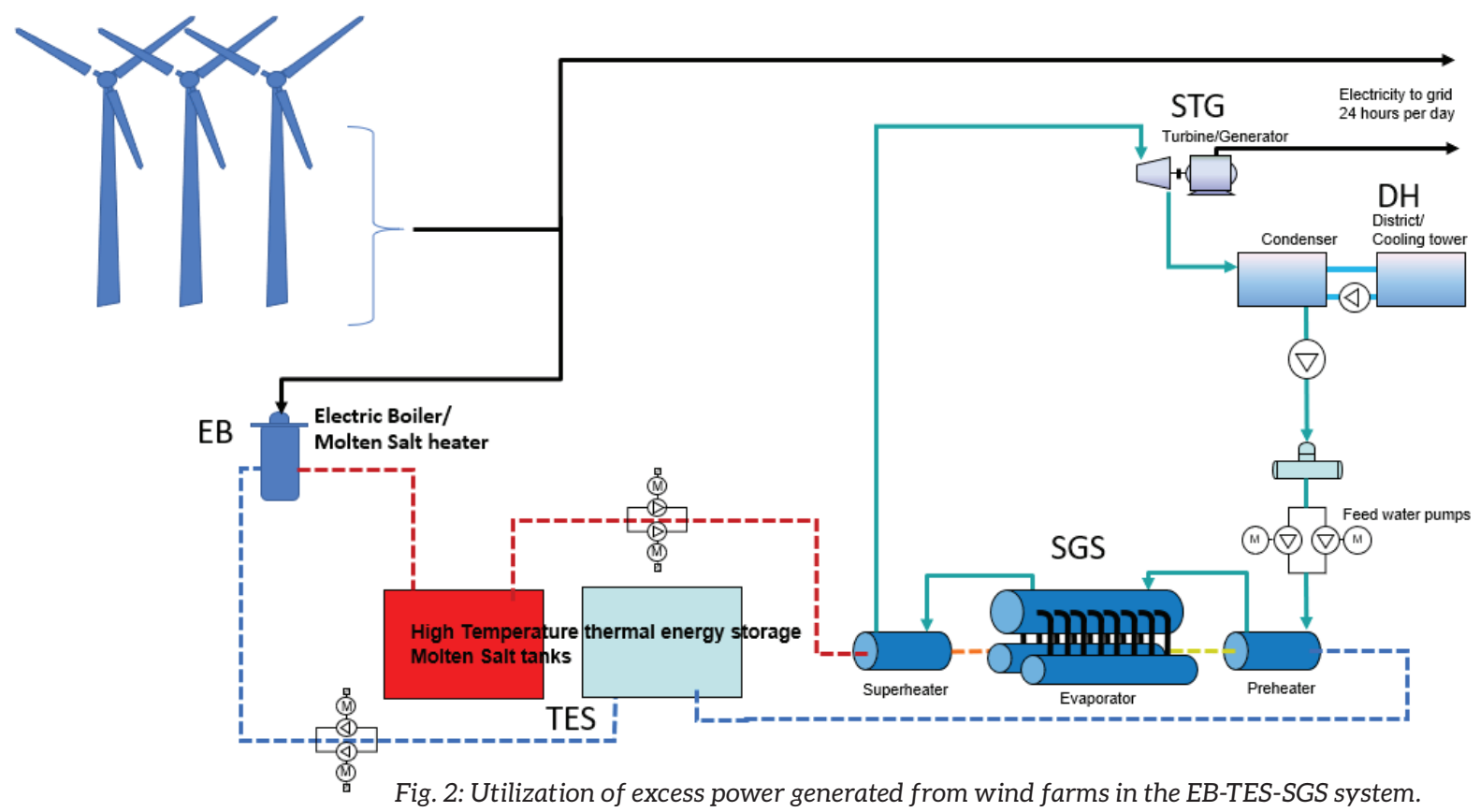




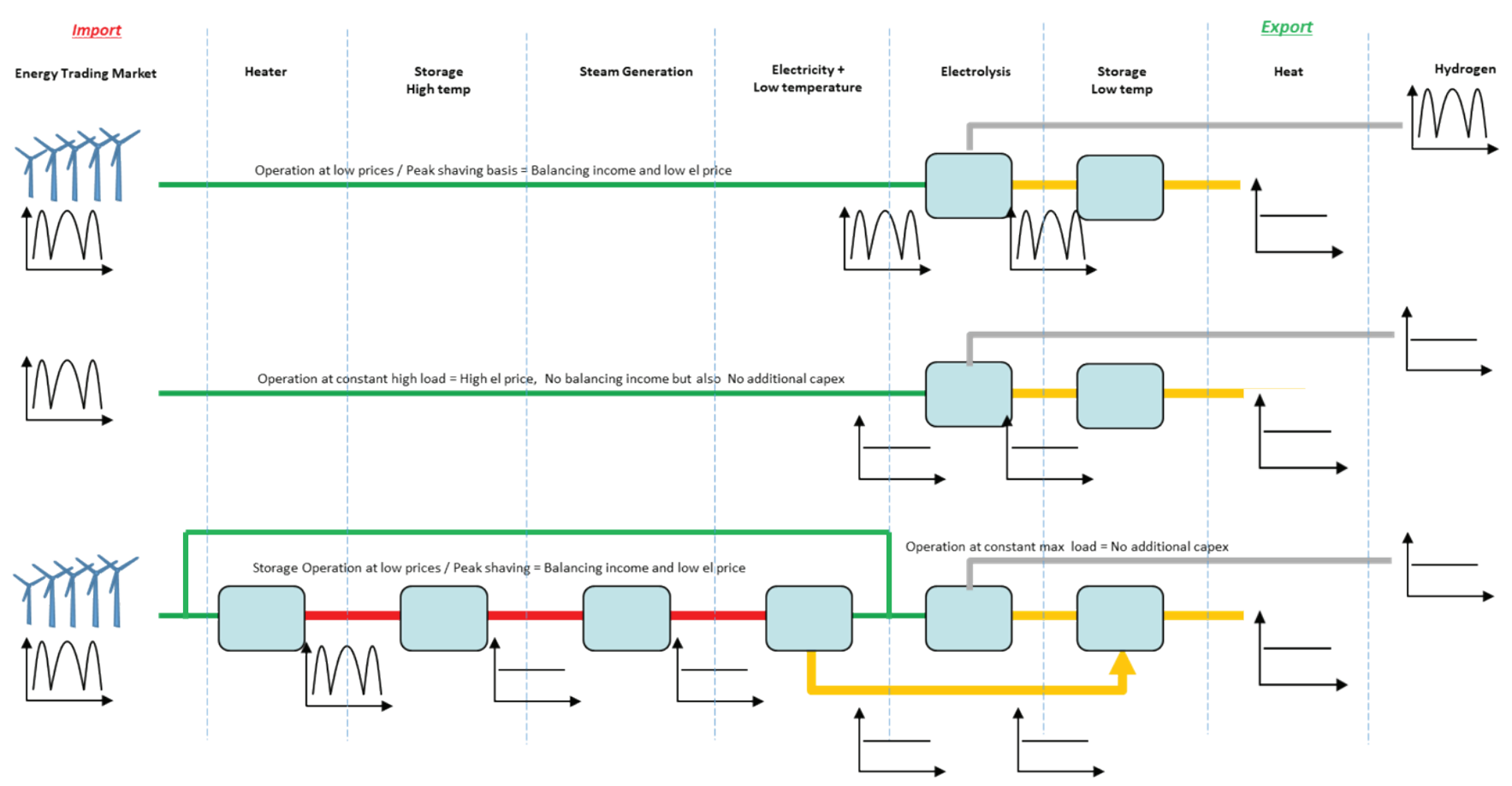

Fig. 3a. Comparative illustration of the PtX/Hydrogen configuration with respect to the import of electricity.

TABLE I

COMPARATIVE SCENARIOS OF THE P-X-HYDROGEN CONFIGURATION WITH RESPECT TO THE IMPORT OF E:ECTRICITY \& INTEGRATION OF HIGH-TEMPRETURE ENERGY STORAGE.

\begin{tabular}{|c|c|c|c|c|c|}
\hline Scenario & Philosophy Description & \multicolumn{2}{|c|}{ CAPEX Vs. Availability } & \multicolumn{2}{|c|}{ OPEX Vs. Revenue } \\
\hline Scenario $\mathrm{A}$ & $\begin{array}{l}\text { Importing electricity during low prices, } \\
\text { fluctuating production of Hydrogen }+ \text { steady } \\
\text { heating due to PTES }\end{array}$ & \multicolumn{2}{|c|}{$\begin{array}{l}\text { Optimized Electrolysis } \\
\text { CAPEX + high-capacity } \\
\text { factor }\end{array}$} & \multicolumn{2}{|c|}{$\begin{array}{l}\text { Controlled OPEX }+ \\
\text { High revenue stream }\end{array}$} \\
\hline Scenario B & $\begin{array}{l}\text { Importing electricity all the time regardless of } \\
\text { the prices, constant production of Hydrogen }+ \\
\text { steady heating due to PTES }\end{array}$ & \multicolumn{2}{|c|}{$\begin{array}{l}\text { High Electrolysis CAPEX + } \\
\text { high-capacity factor }\end{array}$} & \multicolumn{2}{|c|}{$\begin{array}{l}\text { High OPEX + High } \\
\text { revenue stream }\end{array}$} \\
\hline Scenario C & $\begin{array}{l}\text { Importing electricity during low prices }+ \\
\text { HTTES, constant production of Hydrogen }+ \\
\text { steady heating due to PTES }\end{array}$ & \multicolumn{2}{|c|}{$\begin{array}{l}\text { Optimized Electrolysis } \\
\text { CAPEX + high-capacity } \\
\text { factor }\end{array}$} & \multicolumn{2}{|c|}{$\begin{array}{l}\text { Controlled OPEX + } \\
\text { High revenue stream }\end{array}$} \\
\hline Scenario & Philosophy Description & CAPEX & Productivity & OPEX & Revenue \\
\hline Scenario $\mathrm{A}$ & $\begin{array}{l}\text { Importing electricity during low prices, } \\
\text { fluctuating production of Hydrogen }+ \text { steady } \\
\text { heating due to PTES }\end{array}$ & $\bullet \bullet$ & $\bullet$ & $\bullet \bullet$ & 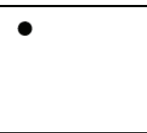 \\
\hline Scenario B & $\begin{array}{l}\text { Importing electricity all the time regardless of } \\
\text { the prices, constant production of Hydrogen }+ \\
\text { steady heating due to PTES }\end{array}$ & $\bullet$ & $\bullet \bullet$ & $\bullet$ & $\bullet \bullet$ \\
\hline Scenario C & $\begin{array}{l}\text { Importing electricity during low prices }+ \\
\text { HTTES, constant production of Hydrogen }+ \\
\text { steady heating due to PTES }\end{array}$ & $\bullet \bullet$ & $\bullet \bullet$ & $\bullet \bullet$ & $\bullet \bullet$ \\
\hline
\end{tabular}




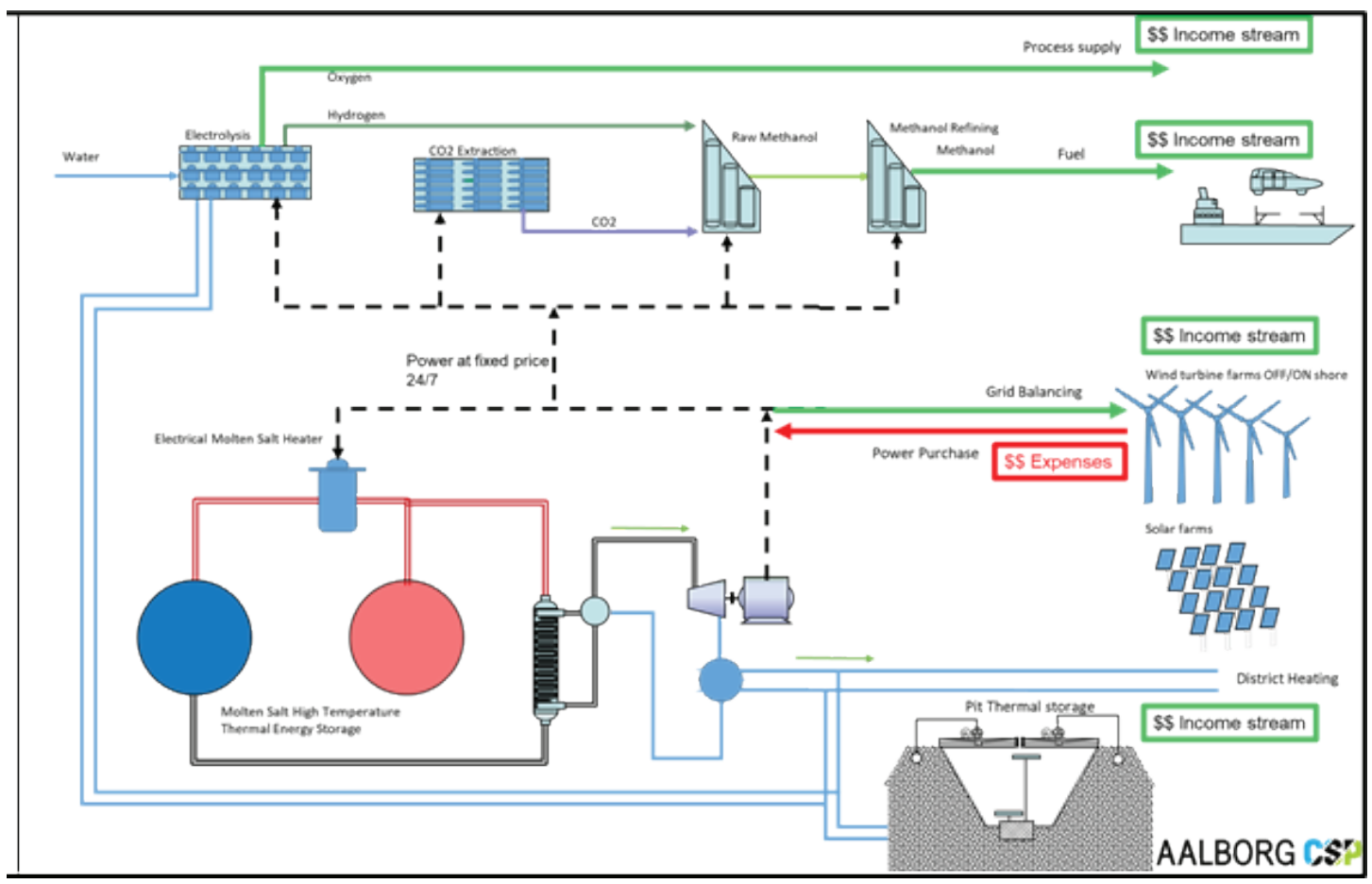

Fig. 3b. Multiple Income Streams of the PtX/Hydrogen Configuration based on Thermal Storage Intehration with Respect to Import of Electricity.

In Figure $3 \mathrm{~b}$, the integration of an electrified Molten Salt Thermal Energy Storage (MS-TES) to the PtX configuration is illustrated. The illustration is presented with respect to the multiple income streams from: electricity, hydrogen, and heating provided to district heating network.

\section{Retrofitting of CPP}

\section{with Power-to-X-to-Power}

This paper presents a viable energy storage solution that can be implemented commercially in full scale and contribute to receiving both national and international $\mathrm{CO} 2$ reduction targets. The objective is to make a proof-of-concept by using a CPP or a renewable energy supplier (e.g. biomass plants) as a demonstration host to document the technological and commercial feasibility [1-3]. Figure 4 illustrates a typical layout of an existing CPP that generates both electricity and district heating (DH). The CPP components outlined to the right is to be replaced by the EB-TES-SGS system outlined to the left to illustrate the retrofitting concept.

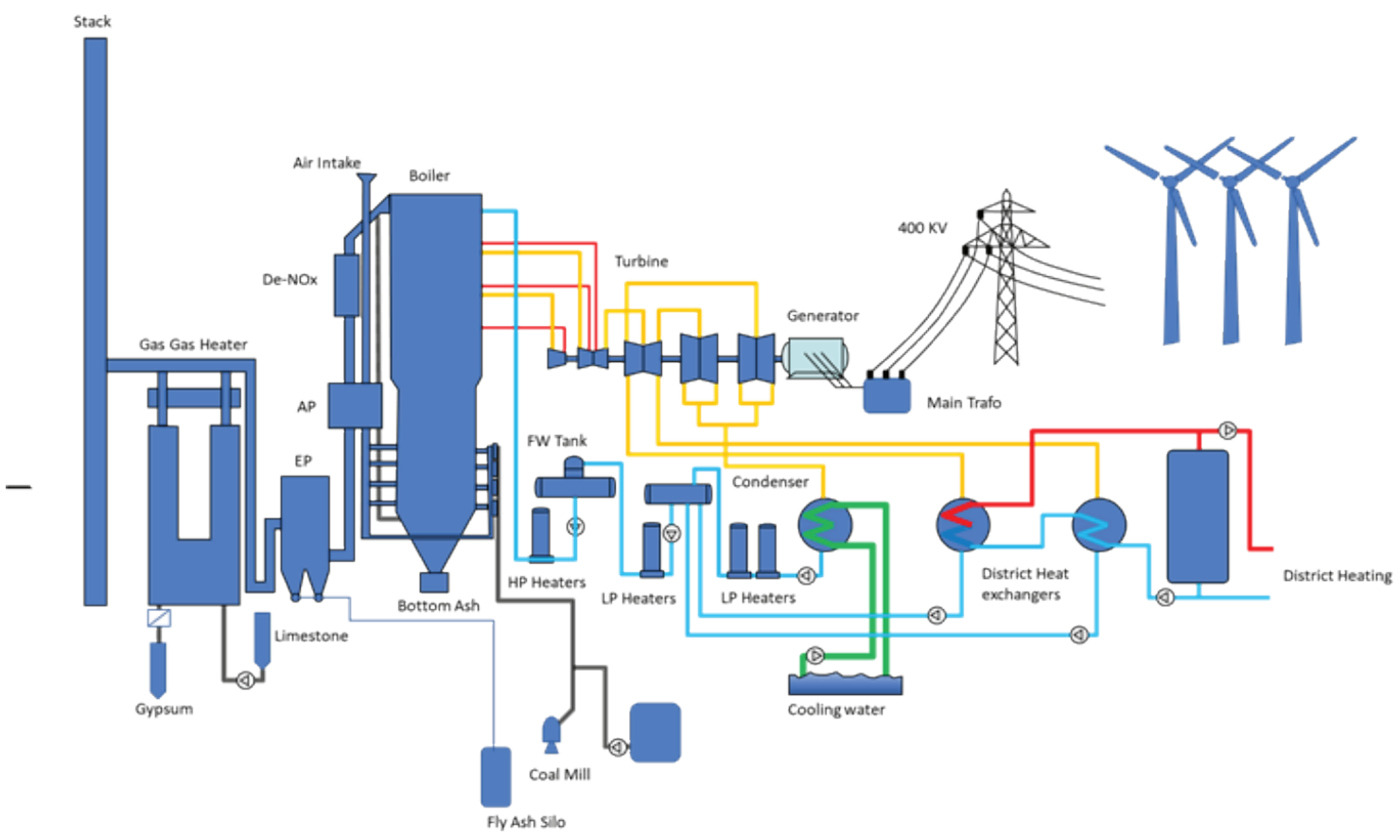




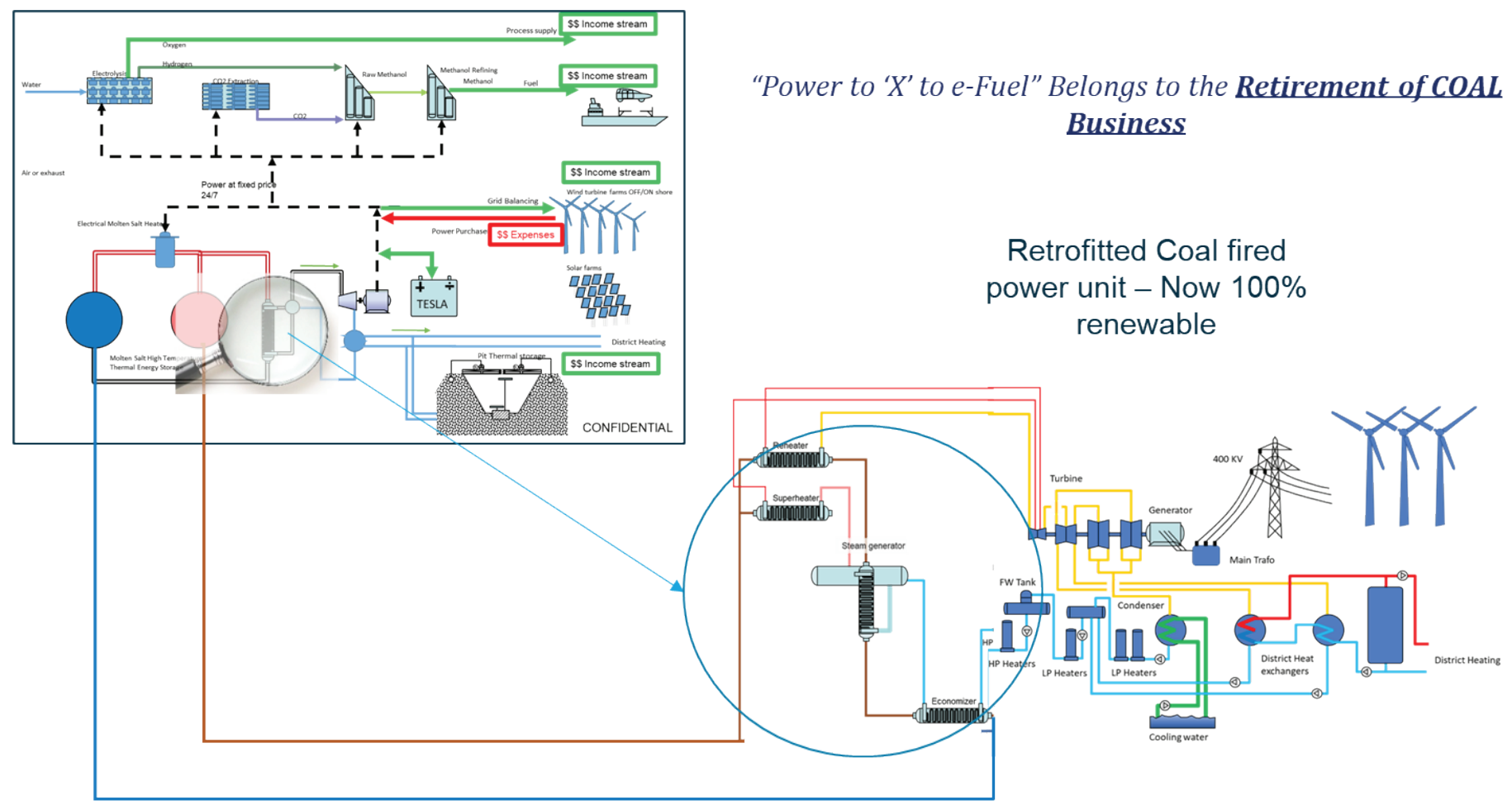

Fig. 4: A Typical CPP Including Retrofitting Proposal with Re-used Existing Assets (i.e STG)

The retrofitting concept, as shown in Figure 4, includes a replacement of main CPP components, such as the boiler and chimney. These are replaced by a package consisting of an electrical boiler (EB), a steam generation system (SGS) and a thermal energy storage (TES) system. This package is integrated with the remaining components of the CPP including the STG and high voltage equipment.

The proposed solution contributes to the grid stability in the following way. Excess power production from e.g. wind and PV is utilized to drive an EB and stored as thermal energy in a high-temperature TES.

By doing so, it is possible to improve grid stability during periods of excess electricity production. During times of power-outage in the grid, the discharge of the TES is activated together with a novel SGS, which converts hot molten salt (MS) into high-pressure superheated steam. The steam drives a turbine and generates electricity to the grid through a Rankine Cycle. The exhaust steam is condensed into hot water and injected directly into the district heating network.

\section{Conclusion and Remarks}

This section briefly summarized the findings and remarks from this paper in the following point:

- $\quad$ Power-to-X-to-Power concept strongly belongs to the coal sector, whether in regrads to retirement of the $\mathrm{CPP}$, or in regards to reducing the dependency on the coal, hence, reducing CO2 emmissions.

- Intgrating as much of possible applications is the key of maximizing the benefit from adopting the Power-to-X-to-Power concept.
In EU market, district heating demand is high, hence, it is very encouraged to include district heating as an important focus within the Powerto-X-to-Power sector.

- In the MENA region market, district cooling is potentially a very important sector to be considered within the Power-to-X-to-Power sector.

- Investing in integration of high-temperature thermal storage within the configuration of $\mathrm{P}-\mathrm{X}$ Hydrogen gives possibility to better the tecnoeconomical case. However, a business case is worth investigation to conclude the comparison between Scenario B and Scenario C.

\section{REFERENCES}

[1] H. Soliman and P. Badstue, "Contribution of power to $\mathrm{X}$ to power in retrofitting of coal fired power plants and grid stability", Proc. Of Solar PACES, October, 2020.

[2] H. Soliman, P. Badstue and S. Larsen, "Contribution of power-to-X-to power in retrofitting of coal-fired power plants", Proc. Of 4th Generation District Heating Technologies and Systems (4DH), September, 2020.

[3] P. Badstue and H. Soliman,"Aalborg_CSP_Coal_ transition_Energy_Storage"_Compnay Presentation, October, $20 \overline{19}$.

[4] "Denmark Electricity Prices", Available: https://energinet.dk/Om-nyheder/Nyheder/2018/02/22/Danmark-har-samme-elprissom-nabolande-i-over-8000-af-aarets-timer, February, 2018. 